\title{
The ageing of parent carers: classed and gendered care-giving patterns at higher ages
}

\author{
Ursula Henz ${ }^{1}$ (D) \\ ${ }^{1}$ Department of Sociology, London School of Economics, London, UK \\ Email: u.henz@lse.ac.uk
}

(Accepted 29 April 2021; first published online 12 July 2021)

\begin{abstract}
Increasing longevity has led to a rising number of adult children who are at higher ages when they provide care for their parents. Drawing on the lifecourse approach and exchange theory, the paper addresses similarities and differences in parent care between late middle-aged and older adult children. The study uses the UK Household Longitudinal Study, restricting the analysis sample to individuals aged 50 and older with a living parent or parent-in-law. It presents multivariate models to examine differences between late middle-aged (aged 50-64) and older (aged 65+) children in being a parent carer, providing intensive care, the duration of parent care and providing selected types of help to parents. The involvement in parent care increases among women up to the end of their seventh decade of life and for men up to their eighth decade of life. At higher ages, the proportion of parent carers decreases more strongly for women than men. Older carers have shorter care-giving episodes than younger carers, but there is no significant difference in the type of care provided. Even past retirement age, parent care remains classed and gendered, with women from lower social classes having the highest likelihood of providing intensive parent care in old age. Having dependent children or living in a non-marital union depress the likelihood of caring for a parent even past retirement age.
\end{abstract}

Keywords: elder-care; informal care-giving; intergenerational relationships; gender

\section{Introduction}

Adult children are an important source of help and care for older people in the United Kingdom (UK). Most parental care needs arise when children are in midlife. However, with increasing longevity, parent care has become more common in the later part of adult children's lives. Whereas in 1990, only 20 per cent of parent carers were between 55 and 64 years old and 4.5 per cent were 65 years or older (Office of Population Censuses and Surveys, Social Survey Division, 1992, own calculations), the figures increased to 33.5 and 9.4 per cent, respectively, in 2017 
(University of Essex, Institute for Social and Economic Research, 2019, own calculations). ${ }^{1}$

This paper examines care-giving for parents or parents-in-law provided by adults aged 65 and older and compares it with the care-giving by adults in late mid-life, that is aged 50-64. Differences in the social and demographic circumstances of the two groups are likely to lead to different levels and socio-demographic patterns of care-giving. Having a living parent(-in-law) at higher ages is a socially selective experience. It is affected by classed patterns of life expectancy (Office for National Statistics (ONS), 2015), which make it more likely for higher-class parents to survive into very old age compared to lower-class parents. In addition, classed and gendered patterns of living arrangements in old age (Martikainen et al., 2019) lead to different likelihoods of having a living parent-in-law.

Most research about informal care-giving focuses on middle-aged adults who have to combine care-giving with paid employment and bringing up their children. These constraints will be less common among care-givers past retirement age, facilitating a more intensive involvement, especially by men, compared to younger ages. However, older carers might experience new constraints like their own or their partners' declining health. Class and gender differences in morbidity (Bartley, 2017; ONS, 2019) might also be reflected in care-giving patterns at higher ages.

Past research has shown that gender differences in informal care-giving decrease at higher ages (ONS, 2007: 22) and even revert (ONS, 2013). However, the majority of care-givers at higher ages provide care for a partner (ONS, 2007: 27, 29) and spousal care in older age groups is characterised by gender equality (Pinquart and Sörensen, 2006; ONS, 2007: 26). Therefore, the shrinking gender differences in informal care-giving at higher ages might not apply to parent(-in-law) carers.

Differences between middle-aged and older parent carers have not been systematically addressed in previous research. The first aim of this paper is to ascertain the prevalence of parent care at higher ages among adults who have a living parent or parent-in-law. The further aims are to examine whether there are differences in the types and duration of parent care between late middle-aged and older children; whether gendered and classed patterns of caring for parents(-in-law) differ between late middle-aged and older children; and whether there are further changes in structural determinants of care-giving for parents(-in-law) when children reach higher ages.

The paper continues with elaborating the background of the study. Then it introduces the data, which are taken from the UK Household Longitudinal Study (UKHLS) (University of Essex, Institute for Social and Economic Research, 2019). The UKHLS includes information about care-giving, the hours of caregiving and about having living parents. After describing the variables and the analysis strategy, the paper presents descriptive results. Then it examines age, class and gender differences by estimating multivariate regression models and comparing characteristics of parent(-in-law) carers above age 64 with those in late middle-age (age 50-64). The paper closes with a discussion of the results. For ease of presentation, the term 'parent care' refers to care-giving for parents or parents-in-law in the rest of the paper. 


\section{Background}

Adults provide care for their ageing parents(-in-law) at different times of their lives. The lifecourse approach conceives of parent care as an age-graded event that unfolds in the cultural and institutional context of individual lives (Giele and Elder, 1998). According to this approach, the prevalence, timing and duration of providing parent care will also vary with the changing circumstances of the individual in other life domains. For example, child care and full-time employment can restrict individuals' time for parent care, leading to an exploration of alternatives to their own full engagement.

These explorations can be examined from an exchange theoretical perspective (White and Klein, 2002). According to this theory, individuals will consider the costs and rewards associated with alternative possible care-giving arrangements. Among these alternatives, they will choose the one that offers them the most rewards relative to its costs, where rewards and costs can take many forms, including time, money or psychological wellbeing. In this vein, a full-time employed child might curtail their involvement in parent care if other sources of care can be mobilised. In particular, the child might limit their involvement to less-intensive caregiving, shorter durations or particular types of help, or they might not get involved at all. Past research has shown that full-time employment reduces the likelihood of becoming a care-giver (Henz, 2004; Leopold et al., 2014; Moussa, 2019). If this barrier falls at the time of retirement, the rates of providing parent care should increase accordingly (Hypothesis 1).

Most people care for their parents during mid-life, when the proportion of informal carers is higher among females than males (ONS, 2020). The gender gap in elder-care has been explained by childhood socialisation into gender roles that ascribe elder-care as a 'natural' responsibility of women (Cancian and Oliker, 2000). More recently, social constructionists have argued that women and men perform gender in their everyday life (West and Zimmerman, 1987). According to this 'doing gender' approach, female carers present themselves as competent members of their sex category by providing parent care. Higher rates of parent care among women have also been related to adult daughters maintaining more intimate bonds with their parents compared to sons (Leopold et al., 2014).

In contrast to these normative approaches, exchange theory draws attention to gender differences in the barriers to providing care and the available alternatives. Full-time employment reduces middle-aged men's care-giving more than women's because of men's higher rates of full-time employment. Therefore, retirement should lead towards an alignment of men's and women's involvement in providing parent care (Hypothesis 2).

Another possible barrier to parent care is the carer's deteriorating health at higher ages. Health problems also affect children's spouses, resulting in competing care demands. Altogether, health problems at higher ages might lead to limiting parent care to less-intensive care-giving, shorter durations or less-demanding types of help, or not getting involved at all (Hypothesis 3).

As women tend to have higher levels of morbidity (ONS, 2019), health problems might reduce their provision of parent care more strongly than men's. As most women have older spouses, they are also more likely to face spousal care demands. 
Declining health at higher ages would therefore predict a stronger limitation of parent care among females than males (Hypothesis 4).

Exchange theory also draws attention to the role of social class in providing parent care by highlighting classed alternatives to providing hands-on care. Higher economic resources give individuals from higher social classes the option of purchasing care for their parents(-in-law) whereas children from lower social classes have to provide parent care or rely on care provided by the state. Da Roit's (2007) qualitative study describes such classed behaviour for Italy. These patterns might be reinforced by classed attitudes. Lower-class families tend to have a stronger family orientation (Silverstein and Bengtson, 1997) and higher preferences for family care (Klie and Blinkert, 2002). Both mechanisms suggest higher levels of involvement in parent care in lower-class families compared to higher social classes. At higher ages, class differences could change because of classed patterns of morbidity (Bartley, 2017): higher levels of morbidity in lower-class children might depress their involvement. Therefore, class differences should weaken at higher ages (Hypothesis 5).

Past research into educational or class differences in informal care-giving have produced mixed results. ${ }^{2}$ Brandt et al. (2009) observed lower levels of helping parents among individuals with a low level of education compared to those with a high level of education in an analysis of several European countries; they did not find differences by education in the likelihood to provide care. The British study by Arber and Ginn (1992) reported higher levels of care-giving in lower social classes but this mainly applied to co-resident care-giving. Grigoryeva (2017) and Leopold et al. (2014) did not find any significant differences by educational level in their analyses of caring for parents. A possible explanation for the weak and varied findings could be the large heterogeneity of care provision. In particular, it might be important to distinguish between different intensities of care-giving - the costbenefit calculations when providing intensive care will involve starker choices than those for lighter forms of care-giving or just helping a parent. This would lead to stronger class differences in intensive care-giving compared to lighter forms of care-giving. The hypothesised decrease in class differences at higher ages should then be more marked for intensive care-giving than for less-intensive forms (Hypothesis 6).

In addition to the gendered and classed patterns of care-giving, other aspects of the caring context change as care-givers reach higher ages. Past studies have conceptualised young children as competing commitment of parents (Dautzenberg et al., 2000; Henz, 2006) but the empirical findings have been mixed. Some studies found a negative effect of having (young) children on becoming an informal carer (Henz, 2006; Brandt et al., 2009; Leopold et al., 2014), whereas others did not find any significant effect (Spiess and Schneider, 2003; Dautzenberg et al., 2000; Grigoriyeva, 2017). Although only a minority of individuals in late middle-age and beyond are living with a dependent child, the proportion has been rising among men (Henz, 2014). This trend to late fatherhood might sustain limitations to providing parent care into higher ages.

The majority of parents aged 50 or older have only non-dependent children. Their role might fundamentally differ from that of young children because older children can support their parents in looking after the oldest generation. 
Non-dependent children should not form an obstacle to providing parent care (Hypothesis 7).

Furthermore, co-resident partners can provide support for care-givers although they can also make additional demands of the carer. Past research seems to support the latter: unmarried individuals are more likely to be informal carers (Henz, 2006; Leopold et al., 2014; only women: Grigoryeva, 2017) and provide more hours of care than married carers (Sarkisian and Gerstel, 2004). In recent decades, an increasing number of individuals have been living in non-marital co-habiting relationships in mid-life and beyond (ONS, 2012), which raises the question of older co-habiting individuals' involvement in care-giving. Although there are strong similarities between co-habitation and marriage for older people (Carr and Utz, 2020), the fact that the partners prefer a non-marital union can indicate stronger individualistic orientations in co-habiting unions compared to marriages (Hamplova and Le Bourdais, 2009). Henz (2010) observed that co-habitors were less likely than married individuals to be involved in caring for their parents-in-law. Noël-Miller's (2011) finding that older co-habitors are less likely to care for their partners compared to married individuals indicates a lower commitment of co-habitors to caregiving obligations at higher ages. These findings predict a lower involvement in parent care among individuals in co-habiting unions compared to marriages (Hypothesis 8).

The following analyses will examine differences in providing parent care between adults in late mid-life and older adults. It includes testing the hypotheses of declining gender and class differences, as well as the relevance of partnership and child configurations at higher ages.

\section{Methods}

\section{Data}

The UKHLS is a panel study of originally about 40,000 households in the UK. This study uses the first nine panel waves from 2009 to 2017, which includes information about 34,376 individuals aged 50 years or older with a full interview, comprising 174,872 person years. For all multivariate analyses, the analysis sample is further restricted to person years when individuals had at least one living parent or parent-in-law. This information is derived from the yearly household grids and the bi-annual module about family networks. The values were imputed in survey years without the module if there was sufficient information, reducing the sample to 31,671 individuals and 158,049 person years.

\section{Variables}

In each panel wave, the respondents were asked whether there is 'anyone living with you who is sick, disabled or elderly whom you look after or give special help to...?' and whether they 'provide some regular service or help for any sick, disabled or elderly person not living with you?' If the care recipient lived in the same household as the respondent, parent carers can always be identified. For care recipients in another household, respondents reported the relationship to up to two persons for whom they cared, with 'parent/parent-in-law' being one of the pre-coded options. Respondents reported the combined hours of caring for all care recipients 
as one of seven pre-coded categories. We combine these into two categories of '1-19 hours' and '20 hours or more'. The derived variable for the hours of parent(-in-law) care has 1.2 per cent missing values, mostly because individuals cared also for someone who was not a parent(-in-law). In the rest of the paper, we refer to care-giving for 20 or more hours per week as 'intensive' care. The threshold has been informed by the literature (e.g. Department for Work and Pensions, 2019).

Four panel waves $(2011,2013,2015,2017)$ collected information about help exchanged between parents and their adult children. The module asked about eight types of help that children gave regularly or frequently to their parents, including financial help, cooking meals and helping with basic personal needs.

We distinguish three living arrangements: living alone, living in a marital relationship and living in non-marital co-habiting relationships ('Living as a couple'). The respondent's child configuration at the time of the interview is captured by two dummy variables for having a 'Dependent child' or 'No [living] child', with the reference category of having only non-dependent children. The two dummy variables, 'Full-time work' and 'Part-time work', map the respondent's paid-work involvement, with the reference category 'Not in paid work'. The dummy variable 'Cares for partner' has been derived from the question about caring for someone in the same household. Analyses of intensive care-giving do not include individuals who care for their partner because the hours of parent care cannot be derived if the respondent has multiple types of care recipients.

The measures for respondent's physical and mental health are based on the SF-12 questionnaire (Ware et al., 1996). Both scales have been designed to take values from 0 to 100 , with high values indicating good health. We re-scaled the measures to values from 0 to 1 . In some interviews, the questions were part of the self-completion questionnaire, which contributed to about 6 per cent of missing values in our sample. By imputing values for single years of missing values, this proportion is reduced to 3 per cent. ${ }^{3}$

The UKHLS did not collect consistent information about occupational class for this sample of late middle-aged and older people. Therefore, we use education as a proxy for class - the highest achieved level of education for non-partnered individuals and the higher of the two partners' levels of education for respondents who lived with a partner. The three categories distinguish between a low, middle or high level of education. ${ }^{4}$

The models control for parent(-in-law)'s age as it is associated with their care needs. The age of the oldest living parent(-in-law) was coded to the average number of activities of daily living (ADL) and instrumental activities of daily living (IADL) that people of their year of age could not carry out without help. The transformed variable of parental age ranges from 0.4 to $5.7 .^{5}$ Finally, we control for whether a parent(-in-law) lived in the adult child's household, calendar year (minus 2008) and the number of UKHLS waves in which the individual participated. ${ }^{6}$

Table 1 gives descriptive statistics for the explanatory variables in the final analysis sample after excluding cases with missing values. A total of 15,052 individuals had a living parent or parent-in-law, contributing 60,611 person years. These comprised 5,025 parent carers aged 50-64 (contributing 12,865 person years) and 1,078 parent carers aged 65 or older (contributing 2,508 person years). ${ }^{7}$ The first data column in Table 1 gives the means of the explanatory variables for the person-year 
Table 1. Descriptive statistics for the person-year sample, not weighted ${ }^{1}$

\begin{tabular}{|c|c|c|c|}
\hline & All & Carers & Intensive carers \\
\hline $\mathrm{N}$ person years & 60,611 & 15,373 & 1,901 \\
\hline \multirow[t]{2}{*}{$\mathrm{N}$ individuals } & 15,052 & 5,669 & 1,043 \\
\hline & $\begin{array}{l}\text { Mean (person } \\
\text { years) }\end{array}$ & $\begin{array}{l}\text { Percentage of } \\
\text { parent carers }\end{array}$ & $\begin{array}{l}\text { Percentage of } \\
\text { intensive parent } \\
\text { carers }\end{array}$ \\
\hline Total & & 25.4 & 3.2 \\
\hline Female & 50.9 & 30.5 & 4.6 \\
\hline \multicolumn{4}{|l|}{ Age: } \\
\hline $50-59$ & 68.5 & 22.5 & 2.7 \\
\hline $60-69$ & 27.8 & 32.0 & 4.3 \\
\hline $70-79$ & 3.6 & 28.7 & 4.5 \\
\hline $80+$ & 0.1 & 16.5 & - \\
\hline \multicolumn{4}{|l|}{$\begin{array}{l}\text { Marital status (Ref. Married } \\
\text { couple): }\end{array}$} \\
\hline No partner & 19.5 & 29.6 & 7.6 \\
\hline Living as a couple & 8.9 & 19.1 & 1.9 \\
\hline \multicolumn{4}{|l|}{$\begin{array}{l}\text { Children (Ref. Only } \\
\text { non-dependent child): }\end{array}$} \\
\hline No living child & 20.5 & 27.6 & 4.9 \\
\hline Dependent child & 19.6 & 16.4 & 1.5 \\
\hline \multicolumn{4}{|l|}{$\begin{array}{l}\text { Paid work (Ref. Not in paid } \\
\text { work): }\end{array}$} \\
\hline Full-time work & 48.1 & 21.3 & 1.6 \\
\hline Part-time work & 16.2 & 28.4 & 3.4 \\
\hline Caring for partner & 3.8 & 25.6 & - \\
\hline $\begin{array}{l}\text { Parent(-in-law) in } \\
\text { household }\end{array}$ & 3.8 & 66.5 & 34.4 \\
\hline \multicolumn{4}{|l|}{ (Couple) level of education: } \\
\hline Low & 29.3 & 24.8 & 5.0 \\
\hline Middle & 36.4 & 26.7 & 2.9 \\
\hline \multirow[t]{2}{*}{ High } & 34.3 & 24.5 & 2.1 \\
\hline & & $\begin{array}{l}\text { Mean in sample of } \\
\text { carers }\end{array}$ & $\begin{array}{l}\text { Mean in sample of } \\
\text { intensive carers }\end{array}$ \\
\hline Age & 57.3 & 58.3 & 58.7 \\
\hline Physical health & 0.487 & 0.495 & 0.475 \\
\hline Mental health & 0.502 & 0.503 & 0.479 \\
\hline $\begin{array}{l}\text { Age of oldest parent } \\
\text { (-in-law) (not transformed) }\end{array}$ & 84.3 & 86.5 & 86.9 \\
\hline
\end{tabular}

Notes: 1 . Only individuals with a living parent(-in-law). Ref.: reference category. 
sample. The second column gives the percentage of carers for each category of categorical explanatory variables, indicating which groups are more or less likely to be carers compared to the 25.4 per cent of carers in the total sample. For continuous variables, the column gives the mean value in the person-year sample of carers. The third column gives the corresponding statistics for intensive care-giving.

\section{Analysis strategy}

We first examine the prevalence of caring for a parent(-in-law) in the whole population aged 50 and older and in the population with a living parent(-in-law). Then we estimate multivariate models for being a parent carer to ascertain age differences before and after controlling for further variables. In addition to whether someone provides care for a parent(-in-law), we also examine age differences with regard to providing intensive care, care duration and helping with particular activities. All analyses are based on the pooled panel data of individuals with a living parent (-in-law). We examine the characteristics of parent carers by estimating random effects logit models with cluster robust standard errors (Cameron and Trivedi, 2005; Andreß et al., 2013).

To allow for non-linear effects of age in the models, age is operationalised by a linear continuous spline function. The first part of the spline function represents a linear age effect starting at age 50 ('Age-50'). The second part represents an additional linear age effect starting at age 65 ('Age-65'), coded as individual's age minus 65 if the individual is 65 years old or older, and zero otherwise. This operationalisation limits the influence of the many parent carers in their fifties on the estimation of age effects for parent carers aged 65 or older. Age differences in the effects of covariates are tested by interactions with a dummy variable for being 65 years old or older $\left({ }^{\prime} \geqslant 65\right)$. For ease of expression, individuals in the 50-64 age bracket are referred to as 'mid-aged' in the rest of the paper.

To ascertain age differences in the duration of care-giving, we estimate a Cox model (Blossfeld et al., 2007). Only caring episodes that start during the panel are included. There are 2,404 such caring episodes with valid information for all variables in the model. They are provided by 2,066 different individuals; 15 per cent of individuals contribute two or more care-giving episodes. The data record 1,721 exits from care-giving, including 340 by parent carers aged 65 or older.

Finally, we test for age differences in eight types of help for parents by estimating the percentages of children who provided this help. They are derived from random-effect models with age and sex as the only covariates. These analyses only use information from the four panel waves for which this information is available and only include individuals who reported caring for a parent(-in-law).

\section{Results}

\section{Descriptive findings: the prevalence of parent care}

Figure 1a gives the proportions of parent carers by age group. Parent care is most common for women and men in their fifties, when 17 per cent of women and 12 per cent of men reported care-giving for a parent or parent-in-law. The proportion of care-givers declined for individuals in their sixties, showing a steeper decline for 
(a)

\section{4}

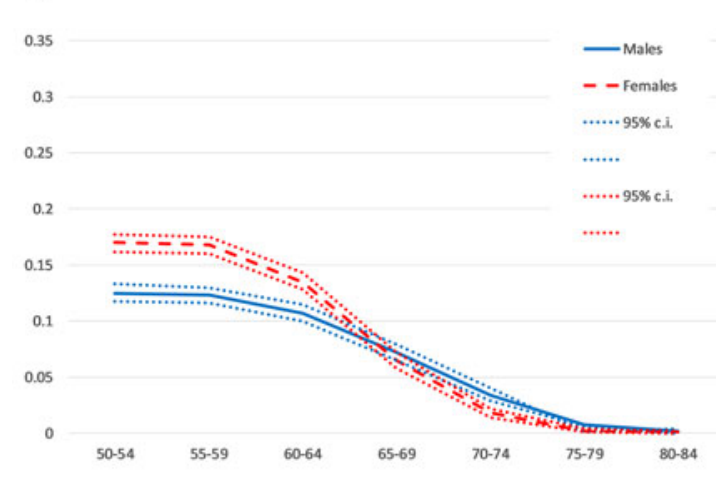

(b)

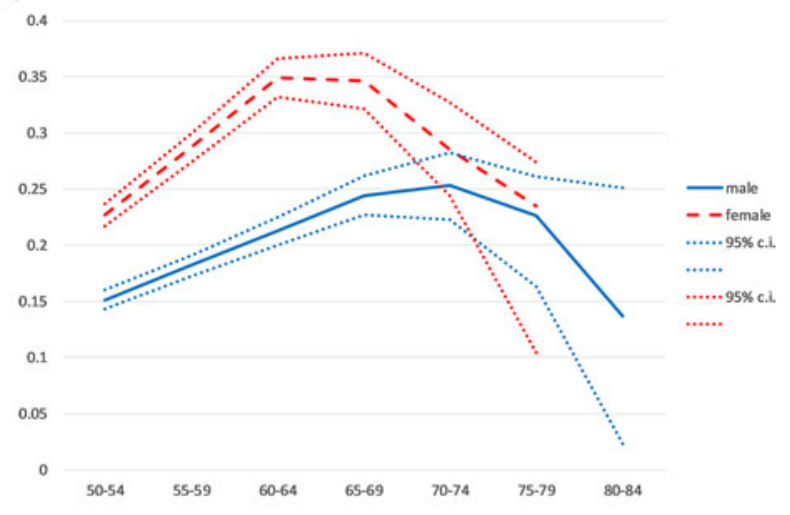

(c) 0.4

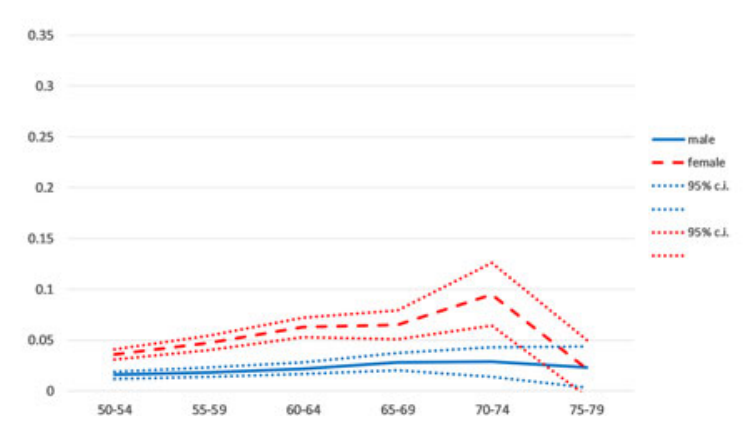

Figure 1. Proportions of parent carers by age and gender. (a) Proportion of parent carers in the population of adults aged 50 or older. (b) Proportion of parent carers in the population of adults with a living parent(-in-law). (c) Proportion of intensive parent carers among adults with a living parent(-in-law).

Note: c.i.: confidence interval. 
women than men. At age 65-69, the proportion of parent carers is the same among men and women. From age 70 onwards, the proportion of parent carers is below 3 per cent of the population, with the proportion of female carers being below that of male carers.

The steeper drop of the proportion of female carers and the higher proportion of parent carers among men at higher ages might reflect the higher proportions of men who had a living parent(-in-law) compared to women. From age 55 onwards, the gender gap in having a living parent(-in-law) amounts to at least four percentage points in favour of men (not shown). Figure $1 \mathrm{~b}$ gives the proportions of parent carers in the population of adults who had at least one living parent(-in-law). These proportions increase to 35 per cent for women in their sixties and to 25 per cent for men in their early seventies. Women's involvement declines rather steeply in their seventies to 24 per cent whereas involvement declines to 14 per cent among men in their early eighties.

Figure $1 \mathrm{c}$ gives the proportion of individuals who provided intensive parent care among those with a living parent(-in-law). The graph shows a higher involvement of women in intensive parent care compared to men for all ages up to age 70-74. Nearly 10 per cent of women aged 70-74 with a living parent(-in-law) provide intensive parent care. At age 75-79, their involvement plummets to about 2 per cent. Men's involvement increases to 3 per cent at age 65-74 and remains at this level for higher ages.

\section{Characteristics of parent carers}

Table 2 gives the results from logistic regression models for providing any care for parents(-in-law). The first model examines whether gender differences and class differences change between children that are younger or older than 65 years. ${ }^{8}$ The significant positive effect of being female proves that women have a higher propensity of care-giving than men at age 50. According to the positive effect of the first spline (Age-50), the likelihood of being a carer increases from age 50 onwards. There is no significant difference between men and women. The significance of the second spline (Age- $65 \times(\geqslant 65)$ ) indicates a decline in the likelihood of caring from age 65 onwards. For women, this decline is steeper than for men because of the significant negative interaction effect between sex and the second spline.

The second model adds a range of explanatory variables, which halve the age effect for the under $65 \mathrm{~s}$ from 0.12 to 0.06 but do not alter the pattern associated with gender. This is also true for the third model, which adds the measures for respondents' health. Figure 2 illustrates the age effects estimated in the third model. It shows a higher involvement of women compared to men up to the late sixties and a steeper decline of their involvement from age 65 onwards, even when controlling for the whole set of covariates. Gender differences in being a parent carer become smaller at higher ages because women are getting less involved.

Model 1 also estimates differences between educational groups and their changes with carer's age. It shows an increased likelihood of being a carer for children in the middle educational group compared to the other two groups. The interaction effects with being 65 years old or older are not statistically significant, that is, there is no change in the differences between educational groups at higher ages.' 
Table 2. Stepwise logit regression models for any care-giving

\begin{tabular}{|c|c|c|c|c|c|c|}
\hline & \multicolumn{2}{|c|}{ Model 1} & \multicolumn{2}{|c|}{ Model 2} & \multicolumn{2}{|c|}{ Model 3} \\
\hline & Coef. & $t$ & Coef. & $t$ & Coef. & $t$ \\
\hline Age-50 & $0.116^{\star \star \star}$ & 12.07 & $0.059^{\star \star \star}$ & 5.76 & $0.062^{\star \star \star}$ & 5.96 \\
\hline Age- $65 \times(\geqslant 65)$ & $-0.109^{\star \star \star}$ & -4.05 & $-0.100^{\star \star \star}$ & -3.76 & $-0.101^{\star \star \star}$ & -3.76 \\
\hline Female & $1.185^{\star \star \star}$ & 11.66 & $1.132^{\star \star \star}$ & 11.15 & $1.136^{\star \star \star}$ & 11.21 \\
\hline Age-50 $\times$ Female & 0.015 & 1.18 & 0.003 & 0.27 & 0.003 & 0.22 \\
\hline Age- $65 \times(\geqslant 65) \times$ Female & $-0.148^{\star \star \star}$ & -3.36 & $-0.157^{\star \star \star}$ & -3.64 & $-0.159^{\star \star \star}$ & -3.64 \\
\hline \multicolumn{7}{|c|}{ Marital status (Ref. Married couple): } \\
\hline No partner & & & 0.077 & 1.00 & 0.064 & 0.80 \\
\hline No partner $\times(\geqslant 65)$ & & & -0.144 & -1.49 & $-0.452^{\star}$ & -2.56 \\
\hline Living as a couple & & & $-0.295^{\star \star}$ & -2.92 & $-0.295^{\star \star}$ & -2.92 \\
\hline Living as a couple $\times(\geqslant 65)$ & & & $-0.535 \dagger$ & -1.88 & $-0.511 \dagger$ & -1.78 \\
\hline \multicolumn{7}{|c|}{ Children (Ref. Non-dependent child): } \\
\hline No living child & & & $0.228^{\star \star}$ & 3.01 & $0.235^{\star \star}$ & 3.11 \\
\hline No living child $\times(\geqslant 65)$ & & & -0.205 & -1.10 & -0.274 & -1.44 \\
\hline Dependent child & & & $-0.240^{\star \star}$ & -3.26 & $-0.256^{\star \star \star}$ & -3.47 \\
\hline Dependent child $\times(\geqslant 65)$ & & & $-1.839^{\star \star}$ & -2.97 & $-1.874^{\star \star}$ & -2.97 \\
\hline \multicolumn{7}{|l|}{ Level of education (Ref. Low): } \\
\hline Middle & $0.236^{\star \star}$ & 3.21 & $0.351^{\star \star \star}$ & 4.96 & $0.324^{\star \star \star}$ & 4.58 \\
\hline Middle $\times(\geqslant 65)$ & 0.017 & 0.14 & & & & \\
\hline High & 0.100 & 1.29 & 0.111 & 1.46 & 0.042 & 0.54 \\
\hline High $\times(\geqslant 65)$ & -0.184 & -1.26 & & & & \\
\hline
\end{tabular}




\begin{tabular}{|c|c|c|c|c|c|c|}
\hline Full-time work & & & $-0.181^{\star \star}$ & -2.97 & $-0.257^{\star \star \star}$ & -4.10 \\
\hline Part-time work & & & 0.025 & 0.37 & -0.032 & -0.46 \\
\hline Cares for partner & & & 0.140 & 1.20 & 0.168 & 1.44 \\
\hline Physical health & & & & & $1.939^{\star \star \star}$ & 8.70 \\
\hline Physical health $\times(\geqslant 65)$ & & & & & 0.338 & 0.82 \\
\hline Mental health & & & & & -0.119 & -0.54 \\
\hline Mental health $\times(\geqslant 65)$ & & & & & 0.311 & 0.77 \\
\hline Parent(-in-law) in household & & & $3.808^{\star \star \star}$ & 23.79 & $3.800^{\star \star \star}$ & 23.82 \\
\hline Parent(-in-law) age transformed & & & $0.476^{\star \star \star}$ & 16.17 & $0.459^{\star \star \star}$ & 15.60 \\
\hline Calendar year & -0.003 & -0.32 & $-0.034^{\star \star \star}$ & -3.91 & $-0.032^{\star \star \star}$ & -3.68 \\
\hline Number of waves & $0.041^{\star \star \star}$ & 3.46 & $0.043^{\star \star \star}$ & 3.68 & $0.040^{\star \star \star}$ & 3.45 \\
\hline Constant & $-4.254^{\star \star \star}$ & -35.01 & $-4.792^{\star \star \star}$ & -34.16 & $-5.569^{\star \star \star}$ & -26.94 \\
\hline $\operatorname{Ln}(($ sigma u $) 2)$ & $2.2342^{\star \star \star}$ & 66.31 & $2.083^{\star \star \star}$ & 63.06 & $2.078^{\star \star \star}$ & 62.96 \\
\hline $\mathrm{N}$ person years & 60,611 & & 60,611 & & 60,611 & \\
\hline $\mathrm{N}$ individuals & 15,052 & & 15,052 & & 15,052 & \\
\hline sigma $u$ & 3.068 & & 2.833 & & 2.826 & \\
\hline Rho & 0.741 & & 0.709 & & 0.708 & \\
\hline
\end{tabular}

Notes: Coef.: coefficient. ( $\geqslant 65$ ): indicator variable 'Aged 65 or older'. Ref.: reference category.

Significance levels: $\dagger p<0.10,{ }^{\star} p<0.05,{ }^{\star \star} p<0.01,{ }^{\star \star \star} p<0.001$. 


\subsection{5}

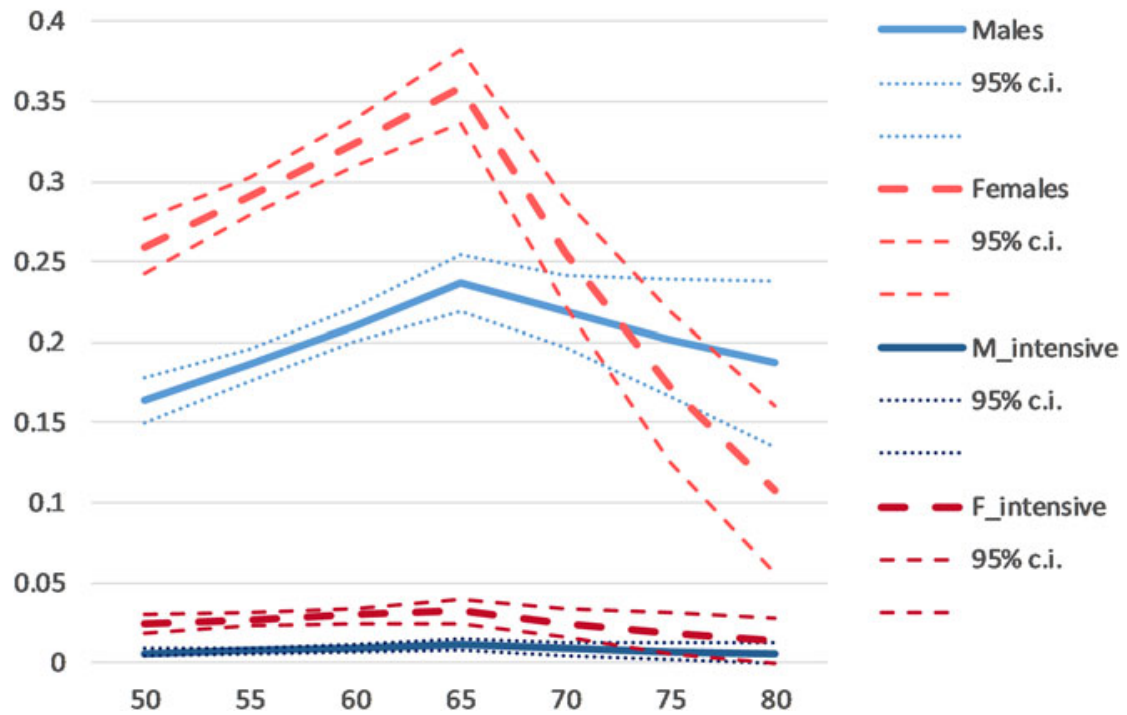

Figure 2. Estimated age effects for being a parent carer, by sex and care intensity. Note: The estimated probabilities refer to married individuals with only non-dependent children and no partner care. All other covariates are set to their overall means. c.i.: confidence interval.

Many of the estimated covariate effects in the full model (Model 3) show the expected patterns - care-giving is positively associated with individual's physical health and the age of the parent. It is negatively associated with having a dependent child and with full-time employment. Under the age of 65 , the care-giving rates of married individuals do not differ from those of individuals who do not live with a partner, in contrast to past research (Henz, 2006; Leopold et al., 2014; Grigoryeva, 2017). However, individuals who live as a couple without being married stand out by being significantly less likely to provide parent care than the two other groups. At higher ages, married individuals have the highest likelihood of being a parent carer, and the involvement in parent care by individuals who live as a couple falls even further behind, though the effect is only weakly significant.

Under the age of 65, childless individuals are more likely to be a carer than individuals with only non-dependent children, who, in turn, are more likely to be a carer than individuals with a dependent child. Above age 65, the negative effect of having a dependent child gets even larger. It is noteworthy that this applies only to men (not shown) because none of the females aged 65 or older had a dependent child.

We find no further significant change in any covariate effect at higher ages, neither in the presented models nor in additional models that tested changes in other covariate effects. The negative association between parent care and full-time work persists at higher ages. Providing care for a partner did not significantly affect the likelihood of parent care. 
Table 3. Stepwise logit regression models for any intensive care-giving

\begin{tabular}{|c|c|c|c|c|c|c|}
\hline & \multicolumn{2}{|c|}{ Model 1} & \multicolumn{2}{|c|}{ Model 2} & \multicolumn{2}{|c|}{ Model 3} \\
\hline Age-50 & $0.108^{\star \star \star}$ & 5.02 & $0.046^{\star}$ & 2.07 & $0.050^{\star}$ & 2.19 \\
\hline Age- $65 \times(\geqslant 65)$ & $-0.135^{\star}$ & -2.34 & $-0.098 \dagger$ & -1.69 & $-0.104 \dagger$ & -1.77 \\
\hline Female & $1.558^{\star \star \star}$ & 7.08 & $1.829^{\star \star \star}$ & 8.08 & $1.802^{\star * *}$ & 8.02 \\
\hline \multicolumn{7}{|c|}{ Marital status (Ref. Married couple): } \\
\hline No partner & & & $0.778^{\star \star \star}$ & 5.77 & $0.698^{\star \star *}$ & 4.87 \\
\hline No partner $\times(\geqslant 65)$ & & & $-0.482^{\star}$ & -2.52 & $-0.813^{\star *}$ & -2.76 \\
\hline Living as a couple & & & -0.246 & -1.17 & -0.263 & -1.24 \\
\hline \multicolumn{7}{|c|}{ Children (Ref. Only non-dependent child): } \\
\hline \multicolumn{7}{|c|}{ Level of education (Ref. Low): } \\
\hline Middle & $-0.533^{\star \star \star}$ & -3.69 & -0.074 & -0.56 & -0.072 & -0.54 \\
\hline Middle $\times(\geqslant 65)$ & -0.011 & -0.04 & & & & \\
\hline High & $-0.967^{\star \star \star}$ & -5.97 & $-0.674^{\star \star \star}$ & -4.49 & $-0.687^{\star \star \star}$ & -4.52 \\
\hline High $\times(\geqslant 65)$ & -0.055 & -0.18 & & & & \\
\hline Full-time work & & & $-1.261^{\star \star \star}$ & -9.85 & $-1.272^{\star \star \star}$ & -9.55 \\
\hline
\end{tabular}


Table 3. (Continued.)

\begin{tabular}{|c|c|c|c|c|c|c|}
\hline & \multicolumn{2}{|c|}{ Model 1} & \multicolumn{2}{|c|}{ Model 2} & \multicolumn{2}{|c|}{ Model 3} \\
\hline & Coef. & $t$ & Coef. & $t$ & Coef. & $t$ \\
\hline Physical health & & & & & $1.284^{\star *}$ & 2.70 \\
\hline Physical health $\times(\geqslant 65)$ & & & & & 0.747 & 0.88 \\
\hline Parent(-in-law) in household & & & $5.429^{\star \star \star}$ & 26.32 & $5.436^{\star \star \star}$ & 26.30 \\
\hline Parent(-in-law) age transformed & & & $0.452^{\star \star \star}$ & 9.37 & $0.433^{\star \star \star}$ & 8.83 \\
\hline Calendar year & -0.024 & -1.43 & $-0.049^{\star \star}$ & -2.68 & $-0.052^{\star \star}$ & -2.88 \\
\hline Number of waves & -0.012 & -0.51 & 0.024 & 1.02 & 0.024 & 1.02 \\
\hline $\mathrm{N}$ individuals & 14,930 & & 14,930 & & 14,930 & \\
\hline sigma $u$ & 3.068 & & 2.795 & & 2.795 & \\
\hline Rho & 0.741 & & 0.704 & & 0.704 & \\
\hline
\end{tabular}

Notes: Coef.: coefficient. $(\geqslant 65)$ : indicator variable 'Aged 65 or older'. Ref.: reference category.

Significance levels: $\dagger p<0.10,{ }^{*} p<0.05,{ }^{* *} p<0.01,{ }^{\star * *} p<0.001$. 
Table 3 gives the estimates from the logit models for providing at least 20 hours of care for parents(-in-law). The first model shows that the likelihood of providing intensive parent care increases up to age 65 and decreases thereafter. Women have a higher likelihood than men but there are no significant interaction effects of age and gender, in contrast to the hypothesis about declining gender differences at higher ages. The pattern remains the same when including the covariates in Models 2 and 3.

The class differences in intensive care-giving show the expected pattern of individuals from the lowest class having the highest likelihood of providing intensive parent care and individuals from the highest class being least likely to provide such care. The pattern does not differ between mid-aged and older adult children, in contrast to Hypothesis 6 . When controlling for having a co-resident parent, there is no longer any difference between individuals from the lowest and the middle educational group. This is because co-residence with a parent(-in-law) is more common in the lowest education group compared to the other two educational groups, and care-giving propensities are particularly high when a parent(-in-law) lives in the same household as the carer. The finding resonates with Arber and Ginn's (1992) observation of class differences in co-resident care-giving.

Most of the covariates show the expected patterns. Providing intensive parent care is positively associated with having no children and having good physical health. It is negatively associated with full-time and part-time work. Under age 65 , individuals who do not live with a partner have an increased propensity for providing intensive parent care, which is in line with past research (Henz, 2006; Leopold et al., 2014; only women: Grigoryeva, 2017). From age 65 onwards, there are no significant differences in intensive care-giving by marital status. A possible reason for the relative decline of non-partnered individuals' care-giving could be the changing composition of this group, which increasingly comprises widowed individuals. Childless respondents are more likely to provide intensive care than parents. There is no significant difference between parents of dependent children and parents of only non-dependent children in providing intensive parent care.

We did not expect a negative association between mental health and intensive parent care as poor health was perceived as a barrier to parent care. The most plausible interpretation is that intensive care-giving has led to a decline in mental health, which has been shown in previous research (Bauer and Sousa-Poza, 2015; Bom et al., 2019).

\section{Types of help and care-giving duration}

The remaining analyses address differences in further aspects of care-giving between younger and older parent carers. Table 4 compares the likelihood of providing different types of help between adult children in the two age groups and by gender. It shows that two activities became somewhat less common among older carers: giving a lift in the car and decorating, gardening or doing repairs. All other activities - shopping; providing meals; help with personal care; washing, ironing, cleaning; help with paperwork; financial help - were provided to the same extent or even more often by older care-givers compared to younger ones. Altogether, there is no indication that older parent carers reduce their involvement 
Table 4. Percentage of parent carers giving selected types of help to their parents, by age group and gender

\begin{tabular}{|c|c|c|c|c|}
\hline & \multicolumn{2}{|c|}{ Age of carer } & \multicolumn{2}{|c|}{ Gender of carer } \\
\hline & $50-64$ & $65+^{1}$ & Males & Females $^{2}$ \\
\hline & \multicolumn{4}{|c|}{ Percentages } \\
\hline Giving lift in car & 59 & $52^{\star \star}$ & 56 & $60^{*}$ \\
\hline Shopping & 68 & $72^{*}$ & 60 & $73^{\star \star}$ \\
\hline Providing or cooking meals & 40 & 41 & 29 & $46^{\star *}$ \\
\hline Helping with basic personal needs & 18 & 20 & 9 & $23^{\star *}$ \\
\hline Washing, ironing or cleaning & 31 & $37^{\star \star}$ & 14 & $42^{\star \star}$ \\
\hline $\begin{array}{l}\text { Dealing with personal affairs, e.g. paying bills, } \\
\text { writing letters }\end{array}$ & 57 & $62^{\star *}$ & 54 & $59^{\star \star}$ \\
\hline Decorating, gardening or house repairs & 44 & $39^{*}$ & 55 & $38^{\star \star}$ \\
\hline Financial help & 15 & 16 & 15 & 14 \\
\hline
\end{tabular}

Notes: $\mathrm{N}=4,974$ person years supplied by 3,028 individuals (UK Household Longitudinal Study panel waves from 2011, 2013, 2015 and 2017). Percentages are estimated from a random effects logit model.

Significance levels: 1. Differences from 'Age 50-64': ${ }^{\star} p<0.05,{ }^{\star \star} p<0.01$. 2. Differences from 'Males': ${ }^{\star} p<0.05,{ }^{\star \star} p<0.01$.

Table 5. Cox model for exiting care

\begin{tabular}{lccc}
\hline & Coefficient & $t$ & Percentage change of rate $^{1}$ \\
\hline Aged 65 or older & $0.194^{\star *}$ & 2.69 & 21.4 \\
\hline Female & $-0.208^{\star \star \star}$ & -4.27 & -18.8 \\
\hline In paid work & 0.089 & 1.61 & 9.3 \\
\hline Intensive parent care & $-0.247^{\star}$ & -2.34 & -21.9 \\
\hline Physical health & $-0.554^{\star}$ & -2.40 & -42.5 \\
\hline Mental health & $-0.687^{\star *}$ & -2.68 & -49.7 \\
\hline Parent age (transformed) & 0.021 & 0.88 & 2.1 \\
\hline Parent(-in-law) in household & $-0.251^{*}$ & -2.44 & -22.2 \\
\hline Wald $\chi^{2}$ (8) & 56.2 & & \\
\hline $\mathrm{N}$ person years & 4,217 & & \\
\hline $\mathrm{N}$ episodes & 2,404 & & \\
\hline $\mathrm{N}$ events & 1,721 & & \\
\hline
\end{tabular}

Note: 1 . The coefficient $c$ is transformed to $100 \times(\exp (c)-1)$, which gives the percentage of change in the estimated rate that is associated with increasing the covariate by one unit (Blossfeld et al., 2007: 99).

Significance levels: ${ }^{*} p<0.05,{ }^{\star \star} p<0.01,{ }^{\star \star \star} p<0.001$.

in more-demanding tasks, in contrast to Hypothesis 3. The vast majority of tasks is gendered with higher proportions of women providing help compared to men. Additional analyses (not shown) indicated no change in the gender differences between the two age groups for the eight activities. 
Finally, we examine differences in the duration of care-giving between mid-aged and older children. Nearly half of all care-giving episodes end within a year, 64 per cent within two years and three-quarters within three years. We analyse the care durations by estimating a Cox model. Table 5 gives the estimates from a parsimonious model that excludes most covariates that had no statistically significant effects. It shows that carers aged 65 or older tend to care for shorter durations than younger carers; their rate of exiting parent care is about 21 per cent higher than that of younger parent carers, supporting Hypothesis 3. Women tend to care for longer durations than men; their rate of leaving care is about 19 per cent lower than that of men. Individuals with poor mental or physical health are more likely to stop providing parent care. Care episodes tend to be longer if an individual provides intensive care. We estimated further models to test for differences in the effects of covariates between the two age groups but none of these was statistically significant.

\section{Discussion}

This study extends analyses of parent care to higher ages by paying attention to the particular contexts of older people who care for their parents or parents-in-law. This context differs between mid-aged and older children because older individuals participate less in paid work, have older children and parents with higher care needs, among others. The study involves first and foremost identifying whether individuals have a living parent or parent-in-law. The main question underlying this research is whether the involvement in parent care by children in their late sixties and older differs from that by children in their fifties and early sixties. The descriptive analyses show that the small absolute number of parent carers at higher ages masks high rates of involvement among individuals who have a living parent (-in-law). In the latter group, the proportion of individuals who provide care for their parents(-in-law) is highest in the seventh and early eighth decade of life. The provision of parent care starts to decline for women in their early seventies and for men in their early eighties. Although the age trends roughly correspond to those predicted in Hypotheses 1 and 3, the multivariate models have shown that retirement from full-time work and declining health are not the main explanatory factors behind the trends.

\section{Class and gender differences}

One focus of the study concerns gender differences and their possible changes with age. The models show higher levels of care-giving by women and declining gender differences at higher ages. Although this confirms Hypothesis 2, the pattern hardly changes when controlling for full-time work, in contrast to the hypothesis. Hypothesis 4 predicted a stronger decline of female than male care-giving at higher ages. Although the analyses show this pattern, it hardly changes when controlling for carer's health, in contrast to Hypothesis 4 . The persistence of the gender differences and their changes at higher ages in the multivariate models indicate that they are not related to changes in the gendered barriers to care-giving in the form of fulltime employment and health problems. 
Hypotheses 5 and 6 predicted decreasing class difference at higher ages, measured here as differences between educational groups. The analyses confirmed class differences in caring for a parent(-in-law) but they did not show any changes at higher ages, contradicting the hypotheses. These persistent class differences at higher ages also indicate that health constraints are of limited importance for providing parent care at higher ages.

Interestingly, the analyses identify different classed patterns for intensive caregiving and any care-giving. For intensive care-giving, we find the expected pattern of lower educational groups being more likely to provide intensive care and individuals from higher educational groups having a lower likelihood of doing so. The pattern is consistent with parent-child relationships being closer in lower-class families (Silverstein and Bengtson, 1997) and with the idea that higher-class individuals or their parents can buy care services. Purchasing services reduces intensive care-giving but adult children might still be involved in lighter forms of care-giving and by supervising care services (Da Roit, 2007). This could be the reason why we find no significant differences between higher-class and lower-class individuals providing lighter forms of care.

When it comes to providing any parent care, individuals with a middle level of education turned out to be more involved than individuals from the other two educational groups. The finding adds to the inconclusive class patterns of care-giving reported in earlier research ( $c f$. above). It is possible that these patterns result from a simultaneous operation of different factors that are associated with class. In addition to the arguments presented earlier - classed values and the ability to purchase care-reciprocity is another principle that affects the help and care exchanged between generations (Brandt et al., 2009; Leopold et al., 2014). If children who have received or expect to receive large financial transfers from their parents are more likely to provide care than other children, the children in the middle educational group should be more involved in care-giving than those from the lower educational group. Geographical distance is another important factor for care-giving (Brandt et al., 2009; Leopold et al., 2014; Grigoryeva, 2017). Because bettereducated children tend to live further away from their parents (Chan and Ermisch, 2015), geographical distance could explain the lower level of involvement in any parent care among children from the highest educational group. Unfortunately, the UKHLS does not provide sufficient information about the geographical distance to the care recipient to use it in the analyses.

\section{Other differences between mid-aged and older parent carers}

The multivariate analyses did not support expectations that caring for one's partner reduced care-giving to parents. Only one factor associated with parent care at midage lost its significance for care-giving at higher ages: individuals without a partner were more likely to provide intensive parent care at mid-age compared to married individuals but from age 65 onwards both groups display similar levels of involvement. Also in the models for any care, the involvement of individuals without a partner declines at higher ages relative to the involvement of married individuals. At younger ages, many unpartnered individuals are unmarried children, who often have higher rates of co-residence, emotional closeness, and instrumental 
and financial exchanges with parents (Sarkisian and Gerstel, 2004). This differs from the older age group, where an increasing proportion of unpartnered individuals are widowed. The finding challenges the assumption that partner demands are responsible for the lower involvement of married children (Henz, 2006; Sarkisian and Gerstel, 2008). Unfortunately, the analyses cannot determine whether the increasing proportion of widowed children is responsible for the new pattern in the highest age group, or whether the oldest couples are more supportive of each other than younger couples.

Interestingly, most factors associated with parent care at mid-age were stable or became stronger for individuals at higher ages. One noteworthy example is the negative association between living in a non-marital union and providing any parent care. The finding suggests that individuals in non-marital partnerships in late mid-life and beyond - often formed after the breakdown of an earlier marriage (ONS, 2012)-curtail their informal care provision for high-aged parents (-in-law). It supports Hypothesis 8 and expands the evidence about weaker caregiving commitments in non-marital relationships (Henz, 2010; Noël-Miller, 2011).

Another pattern that unexpectedly extended into post-retirement ages is the negative association of having dependent children with providing any parent care. In our sample, only men had dependent children at age 65 or older. Past research has shown that men tend to retire later if they have a dependent child (Dentinger and Clarkberg, 2002; Pienta, 2003). This research reveals another effect of late fatherhood in the form of a weakening involvement in parent care.

The multivariate models also showed that non-dependent children constitute less of a barrier to providing parent care than dependent children, partly confirming Hypothesis 7. However, parents of non-dependent children still provide less parent care than childless individuals, both any care and intensive care. This questions the hypothesised change from dependent children as barriers to non-dependent children as supporters of parent care. Instead the analyses suggest that non-dependent children still put demands on parents that reduce their availability for providing care for their parents(-in-law). Alternatively, one might observe a pattern of path dependency where earlier care arrangements continue even when children's demands decline.

\section{Concluding remarks}

Summing up the findings about differences in parent care between late mid-aged and older children, the analyses demonstrate a high level of involvement, including intensive parent care, at and after age 65, and a drop at the highest ages. Apart from caring for shorter periods, there is no indication of older children curtailing their provision of parent care. The analysis of children providing different types of help for their parents showed a sustained or even increased involvement of older children in demanding types of help compared to mid-aged children. Whereas these findings highlight the capacities of older people, they also raise concern about care-giving burdens of older people, especially of low-educated women, who often provide intensive care in their eighth decade of life. Despite the strong evidence of older children's involvement in parent care, the analyses also highlight a potential vulnerability of older parents(-in-law) to some less-common family patterns in the child generation, like non-marital co-habitation or late fatherhood. 
Although the analyses confirm some of the hypothesised patterns, several results challenge predictions that were derived from exchange theory. Our models can only explain part of the decline of parent care at the highest ages. Although poorer own physical health is associated with a lower involvement in parent care, the size of the estimated effect is moderate and leaves most of the drop unexplained. A possible alternative explanation for the decline in parent care at the highest ages can be found by revisiting the lifecourse approach. One of its premises is that people hold norms about the appropriate ages for many lifecourse transitions (Foner, 1996; Giele and Elder, 1998). Even if there are no clear age norms about filial obligations, there are normative guidelines relating to the appropriate time of life for becoming an informal care-giver (Finch and Mason, 1993). Some research suggests that parent care is a 'normative, mid-life task, especially for women' (Pope et al., 2012: 244). Reaching a high age might constitute a 'legitimate excuse' (Finch and Mason, 1993) for not getting involved in caring for one's parents. Future research should address in more depth the societal expectations about care-giving at higher ages.

The finding of a continued gendered pattern of care-giving for several years after retirement also highlights the lasting importance of gendered attitudes and relationships (Cancian and Oliker, 2000). Furthermore, the analyses provide a new perspective on the role of care-givers' partners. If unpartnered individuals are more likely than married individuals to provide intensive parent care in the younger but not in the older age group, it is wrong to perceive marital partners as a barrier to caregiving in this age group, in contrast to findings at younger ages (Sarkisian and Gerstel, 2008).

The study suffers from several limitations. Firstly, the pooled regression models for providing care only reveal associations but not causal effects. Data restrictions prohibit an analysis of the transition into care-giving. Secondly, despite the large dataset, the number of older carers, especially intensive carers, is too small to examine more nuanced differences by carer's age. Finally, the UKHLS does not include some desirable information, such as information about occupational class for the whole sample, whether care was provided for one's parent or a parent-in-law, and the geographical distance between the respondent and the care recipient. However, the study has a number of strengths. It is the first survey analysis that comprehensively examines the caring profile of older parent carers. An important condition is the availability of information about having a living parent or parent-in-law in the UKHLS. The study also contributes an analysis of the duration of care-giving that captures some of the dynamics of providing parent care.

The recent increase in the proportion of older parent carers is a result of increased longevity in cohorts that had their children early in life. Although one can assume that the numbers of older parent carers will remain high in the coming decades (Murphy et al., 2006), they might decline when cohorts of older parents reach old age who had their children later in life. Until this happens, social policies should direct additional support to intensive parent carers at advanced ages.

Data. All datasets were accessed through the UK Data Service. The UK Household Longitudinal Study was deposited by the University of Essex (SN: 6614, UK Data Service, http://doi.org/10.5255/UKDA-SN-6614-13). 


\section{Notes}

1 In 2000, the figures were 24 and 6.5 per cent, respectively (Office for National Statistics, 2006, own calculations) and in 2009 they reached 28 and 7.1 per cent, respectively (University of Essex, Institute for Social and Economic Research, 2019, own calculations).

2 Most studies into parent care do not control for class but often for the level of education. In the absence of findings about class, we interpret educational level as a proxy for social class.

3 The imputed values are the averages of the values in the adjacent years. Excluding the observations with imputed values does not change the substantive findings of the analyses, though the level of significance drops slightly in the Cox models for the parameters associated with intensive care-giving and mental health. 4 Using individual level of education instead of couple level of education does not change the substantive findings of the models.

5 The numbers were derived by the author from the Social Care Module in Waves 7 and 9 of the UKHLS. The average number of ADLs and IADLs for which a person needed help rises very slowly up to ages in the mid-seventies, when the numbers start to rise markedly.

6 The number is adjusted for the different sub-samples of the UKHLS. It is calculated as $9 \times d / M$, where $M$ is the maximum number of waves administered to the respective sub-sample and $d$ is the number of waves in which the individual participated.

7 Individuals are counted twice if they turned 65 during the study.

8 The findings are the same as from estimating two separate models, one for testing whether gender differences change at higher ages and one for testing whether class differences change at higher ages.

9 The interaction effects of educational groups and being 65 years old or older were not statistically significant in any model. For reasons of parsimony they have been dropped from the second and third models.

\section{References}

Andreß HJ, Golsch K and Schmidt A (2013) Applied Panel Data Analysis for Economic and Social Surveys. Berlin: Springer.

Arber S and Ginn J (1992) Class and caring. Sociology 26, 619-634.

Bartley M (2017) Health Inequality: An Introduction to Concepts, Theories and Methods, 2nd Edn. Cambridge: Polity Press.

Bauer JM and Sousa-Poza A (2015) Impacts of informal caregiving on caregiver employment, health and family. Population Ageing 8, 113-145.

Blossfeld H-P, Golsch K and Rohwer G (2007) Event History Analysis with Stata. Mahwah, NJ: Lawrence Erlbaum.

Bom J, Bakx P, Schut F and van Doorslaer E (2019) The impact of informal caregiving for older adults on the health of various types of caregivers: a systematic review. The Gerontologist 59, e629-e642.

Brandt M, Haberkern K and Szydlik M (2009) Intergenerational help and care in Europe. European Sociological Review 25, 585-601.

Cameron A and Trivedi P (2005) Microeconometrics. Cambridge: Cambridge University Press.

Cancian FM and Oliker SJ (2000) Caring and Gender. Thousand Oaks, CA: Pine Forge Press.

Carr D and Utz RL (2020) Families in later life: a decade in review. Journal of Marriage and Family 82, 346-363.

Chan TW and Ermisch J (2015) Proximity of couples to parents: influences of gender, labor market, and family. Demography 52, 379-399.

Da Roit B (2007) Changing intergenerational solidarities within families in a Mediterranean welfare state. Current Sociology 55, 25-69.

Dautzenberg MGH, Diederiks JPM, Philipsen H, Stevens FCJ, Tan FES and Vernooij-Dassen MJFJ (2000) The competing demands of paid work and parent care: middle-aged daughters providing assistance to elderly parents. Research on Aging 22, 165-187.

Dentinger E and Clarkberg M (2002) Informal caregiving and retirement timing among men and women. Journal of Family Issues 23, 857-879.

Department for Work and Pensions (2019) Informal Carers and Employment: Summary Report of a Systematic Review. Available at https://www.gov.uk/government/publications/informal-carers-andemployment-summary-report-of-a-systematic-review. 
Finch J and Mason J (1993) Negotiating Family Responsibilities. London: Routledge.

Foner A (1996) Age norms and the structure of consciousness: some final comments. The Gerontologist 36, 221-223.

Giele J and Elder G (1998) Methods of Life Course Research. Thousand Oaks, CA: Sage.

Grigoryeva A (2017) Own gender, sibling's gender, parent's gender: the division of elderly parent care among adult children. American Sociological Review 82, 116-146.

Hamplova D and Le Bourdais C (2009) One pot or two pot strategies? Income pooling in married and unmarried households in comparative perspective. Journal of Comparative Family Studies 40, 355-385.

Henz U (2004) The effects of informal care on paid-work participation in Great Britain: a lifecourse perspective. Ageing \& Society 24, 851-880.

Henz U (2006) Informal caregiving at working age: effects of job characteristics and family configuration. Journal of Marriage and Family 68, 411-429.

Henz U (2010) Parent care as unpaid family labor: how do spouses share? Journal of Marriage and Family 72, 148-164.

Henz U (2014) Long-term trends of men's co-residence with children in England and Wales. Demographic Research 30, 671-702.

Klie T and Blinkert B (2002) Pflegekulturelle Orientierungen. In Tesch-Römer C (ed.), Gerontologie und Sozialpolitik. Stuttgart, Germany: Kohlhammer, pp. 197-217.

Leopold T, Raab M and Engelhardt H (2014) The transition to parent care: costs, commitments and caregiver selection among children. Journal of Marriage and Family 76, 300-318.

Martikainen P, Murphy M, Moustegaard H and Mikkonen J (2019) Living arrangements of older persons in 1987-2015 in Finland: trends by age, sex and educational attainment. Ageing \& Society 39, 358-380.

Moussa MM (2019) The relationship between elder care-giving and labour force participation in the context of policies addressing population ageing: a review of empirical studies published between 2006 and 2016. Ageing \& Society 39, 1281-1310.

Murphy M, Martikainen P and Pennec S (2006) Demographic change and the supply of potential family supporters in Britain, Finland and France in the period 1911-2050. European Journal of Population 22, 219-240.

Noël-Miller CM (2011) Partner caregiving in older cohabiting couples. Journals of Gerontology: Psychological Sciences and Social Sciences 66B, 341-353.

Office for National Statistics (ONS) (2007) Focus on Families. Basingstoke, UK: Palgrave Macmillan.

Office for National Statistics (ONS) (2012) Short Report: Cohabitation in the UK. Available at https:// webarchive.nationalarchives.gov.uk/20160105222451/http:/www.ons.gov.uk/ons/rel/family-demography/familiesand-households/2012/cohabitation-rpthtml.

Office for National Statistics (ONS) (2013) What Does the 2011 Census Tell Us About the 'Oldest Old' Living in England \& Wales? Available at https://data.gov.uk/dataset/e3a97004-7053-40cc-9df823f6de44e227/characteristics-of-older-people.

Office for National Statistics (ONS) (2015) Trend in Life Expectancy at Birth and at Age 65 by Socio-economic Position Based on the National Statistics Socio-economic Classification, England and Wales: 1982-1986 to 2007-2011 (Statistical bulletin). Available at https://www.ons.gov.uk/peoplepopulationandcommunity/birthsdeathsandmarriages/lifeexpectancies/bulletins/trendinlifeexpectancyatbirthandatage65bysocioeconomicpositionbasedonthenationalstatisticssocioeconomicclassificationenglandandwales/2015-10-21.

Office for National Statistics (ONS) (2019) Health Survey for England 2018: Adults' Health. Available at https://digital.nhs.uk/data-and-information/publications/statistical/health-survey-for-england/2018.

Office for National Statistics (ONS) (2020) Census Table LC3301EW. Available at https://www.nomisweb. co.uk/census/2011/lc3301ew.

Office for National Statistics, Social Survey Division (2006) General Household Survey, 2000-2001, 3rd Edn (SN: 4518) (Data collection). Colchester, UK: UK Data Service. Available at http://doi.org/10.5255/ UKDA-SN-4518-1.

Office of Population Censuses and Surveys, Social Survey Division (1992) General Household Survey, 1990-1991 (SN: 2937) (Data collection). Colchester, UK: UK Data Service. Available at http://doi.org/ 10.5255/UKDA-SN-2937-1.

Pienta AM (2003) Partners in marriage: an analysis of husbands' and wives' retirement behaviour. Journal of Applied Gerontology 22, 340-358. 
Pinquart M and Sörensen S (2006) Gender differences in caregiver stressors, social resources, and health: an updated meta-analysis. Journals of Gerontology: Psychological Sciences and Social Sciences 61B, P33-P45.

Pope ND, Kolomer S and Glass AP (2012) How women in late midlife become caregivers for their aging parents. Journal of Women \& Aging 24, 242-261.

Sarkisian N and Gerstel N (2004) Explaining the gender gap in help to parents: the importance of employment. Journal of Marriage and Family 66, 431-451.

Sarkisian N and Gerstel N (2008) Till marriage do us part: adult children's relationships with their parents. Journal of Marriage and Family 70, 360-376.

Silverstein M and Bengtson VL (1997) Intergenerational solidarity and the structure of adult child-parent relationships in American families. American Journal of Sociology 103, 429-460.

Spiess KC and Schneider AU (2003) Interactions between care-giving and paid work hours among European mid-life women, 1994 to 1996. Ageing \& Society 23, 41-68.

University of Essex, Institute for Social and Economic Research (2019) Understanding Society: Waves 1-9, 2009-2018 and Harmonised BHPS: Waves 1-18, 1991-2009, 12th Edn (SN: 6614) (Data collection). Colchester, UK: UK Data Service. Available at http://doi.org/10.5255/UKDA-SN-6614-13.

Ware J, Kosinski M and Keller SD (1996) A 12-item short-form health survey: construction of scales and preliminary tests of reliability and validity. Medical Care 34, 220-233.

West C and Zimmerman DH (1987) Doing gender. Gender and Society 1, 125-151.

White JM and Klein DM (2002) Family Theories, 2nd Edn. Thousand Oaks, CA: Sage.

Cite this article: Henz U (2023). The ageing of parent carers: classed and gendered care-giving patterns at higher ages. Ageing \& Society 43, 790-813. https://doi.org/10.1017/S0144686X21000799 